\title{
Impacts of Social Media on Language Learning: A Review of Literature
}

\author{
Yonghong Zhou ${ }^{1, *}$ \\ ${ }^{1}$ Graduate School of Education, University of Pennsylvania, Philadelphia, 19104, Pennsylvania, U.S.A. \\ *Corresponding author.Email:1yhz@upenn.edu.
}

\begin{abstract}
This paper reviews social media impacts on language learning, emphasising social media as language skill development tools and social media as intercultural communication platforms. Specifically, the former focuses on the potential influences of social media as language skills development tools on reading and writing, listening and speaking, respectively; and the latter focuses on the possible impacts of social media as intercultural communication platforms on socio-pragmatic skills and L2 motivation. The result indicates social media merit multiple benefits and functions in the language learning processes, such as adequate authentic input resources, less stressful practice spaces, plenty of intercultural communication opportunities, and enhanced learner collaboration. The study also highlights potential limitations of social media platforms, for example, distraction and conflicting information concerns. At last, several future directions have been proposed for upcoming empirical research.
\end{abstract}

Keywords: Social Media, Language Learning, Language Skills, Intercultural Communication

\section{INTRODUCTION}

The emergence and rapid growth of social media captured the attention of second language researchers. They inspired plenty of studies to explore how social media can be used as educational tools. In fact, an increasing body of studies in various fields, perspectives and methodologies have been conducted and generated fruitful implications. In this respect, it is necessary to develop a synthesis to review what has been studied, what conclusions have been summarized, and what deserves more attention. To be more specific, this review paper endeavours to answer two research questions: the impacts of social media as language skills development tools on language learning and the impacts of social media as intercultural communication platforms on language learning. Those two research questions are of significance because it is commonly recognized that language learning includes both learning linguistic knowledge and intercultural competence development [1]. By reviewing related studies, this study attempts to identify significant findings, frame pedagogical implications for both educators and learners, and conclude theoretical suggestions for future research and practice.

\section{SOCIAL MEDIA IMPACTS}

\subsection{Social Media Definition}

In Kaplan and Heinlein's attempt to define social media, social media are identified as "a group of Internetbased applications that build on the ideological and technological foundations of Web 2.0 and allow the creation and exchange of User Generated Content" [2]. The definition indicates social media is often regarded as an umbrella term with many sub-genres. Moving forward, Kaplan and Haenlein introduce six classifications of social media in specific, including blogs (e.g. Wordpress), social networking sites (e.g., Facebook, MySpace), virtual game worlds (e.g., World of Warcraft), virtual social worlds (e.g., Second Life), content communities (e.g., YouTube), collaborative projects (e.g., Wikipedia). To have a comprehensive understanding, this study tends to adhere to Kaplan and Hoenlein's classification in the following review.

\subsection{Social Media as Language Skills Development Tools}

\subsubsection{Reading and Writing}

In response to the widespread use of social media, 
language teaching and learning researchers look into how social media promotes language instruction regarding different language skills. In particular, it is noteworthy that many studies have explored the potential supportive functions of social media across various dimensions of writing and reading.

For writing, previous research on writing skill development through social media use has empirically concentrated on writing fluency, writing quality and selfefficacy for writing.

According to Lannin, writing fluency is considered as "cohesiveness and coherence of ideas in writing" [3]. In other words, idea generation plays a prominent part in writing fluency enhancement. Noticing students are unable to produce coherent writings owing to apprehension, and lack of ideas, Vikneswaran and Krish develop a case study to examine if the integration of Facebook into formal writing instruction can be helpful. The finding suggests Facebook brings several benefits to writing enhancement $[4,5]$. Importantly, in the collected interview data, students mentioned that their writing fluency had been promoted due to the discussions of ideas on private group pages. That is to say, social media can be supportive by affording collaborative writing platforms for language learners to brainstorm, compose and revise thoughts. This result is in line with Alberth's study, which further argues that situated in an online setting, writers can generate better ideas by accessing various resources on the web [6].

In terms of writing quality, by developing a longitudinal study for a Facebook-assisted writing program, Shin concludes that Facebook facilitates author-reader interactions and allows students to assess and comment on others' writings, and thus provides learners with opportunities to modify their original works and improve grammar, structure, content, organization and word choice [7]. In a similar vein, Wichadee explored how peer feedback in a Facebook-assisted writing class support writing quality enhancement. She comments that peer feedback is significant in improving learners' writing quality and reasons that students are conscious that their work will be viewed by readers and thus be more careful in composing the work [8].

In terms of self-efficacy for writing, it should be noted that the term self-efficacy refers to beliefs in one's capabilities to complete an action and is highly correlated with confidence $[9,10]$. Previous studies reported that some language learners feel unconfident due to their limited linguistic proficiency, especially when their works are presented to the public [11]. This problem can be partly solved by integrating social media into writing instruction. As is noted by Vikneswaran and Krish's study, social media platforms, such as Facebook, include a grammar checker which corrects learners' writing errors automatically. Thus students feel more comfortable in writing since they don't need to worry about grammar and vocabulary [12]. What is more, Nishioka conducted a qualitative study to investigate a social-media-enhanced teaching project in a Japanese writing class. The result indicates students were motivated to write because the social media platform affords them native speakers and authentic readers. Specifically, students felt more confident and more willing to write because they believed the native speakers read their writings with a genuine interest [13].

Though a plethora of research regarding social media impacts on language learning skills has been conducted, empirical studies focusing on reading are still limited [14]. Having said that, in a survey conducted by Kabilan et al., the collected data reveal reading information from social media generally increases learners' reading motivation, and many learners claimed those online reading activities improve their reading skills [15]. Though Kabilan et al.'s study did not explain what specific aspect of reading skills they have developed, in a more recent exploratory research of Abdullah, the finding suggests that social media provide learners with texts and information of a wide range, and thus may lead to reading skills enhancement, for instance, skimming [16].

\subsubsection{Speaking and Listening}

Though there is still a dearth of studies investigating how social media influences language learners' speaking proficiency, a growing body of research with different study methods has been noticed. Most of them notably explore the educational affordances of social media as output spaces.

According to Brown, speaking is regarded as a reactive process that receives and produces information [17]. Based on the recognition, Namaziandost and Nasri posit speaking skill is difficult to develop in EFL traditional classrooms because students not only need to be equipped with adequate linguistic abilities, but also need to build up social connections for interactions. Bearing the essential issue in mind, they considered social media as a potential remedy and initiated a survey for exploration. According to the self-reported information, the function of social media as a practice tool has been highlighted. The collected information indicates that most students believe talking to native speakers via social media motivates them to practice and effectively improve their speaking proficiency [18].

Similarly, Mustafa maintains that speaking skills have constantly been a headache for ELF learners because English is not part of learners' daily lives. She hypothesizes social media applications, for example, Skype, YouTube and WhatsApp, which provide adequate connections with other English speakers and plenty of practice opportunities, can fulfill the lack. Indeed, the finding on the experiment data concludes that 
all three social media platforms contribute to learners' speaking skills enhancement. In particular, it has been noticed that learners' oral productions have improved on content, word usage, grammar accuracy, and fluency [19]. It might seem to wonder how YouTube as a receptive tool enhances learners' speaking proficiency. In fact, it can be partly explained by another experimentbased study that Ilyas and Putri generated. The researchers argue that in learning speaking via YouTube, students can practice by repeating what they have heard. In this regard, students became more confident to practice speaking without worrying about mistakes [20].

Similarly, listening is also believed to be hard to acquire for listening skill development, especially in EFL contexts. As such, several studies tried to figure out if social media can be a remedy from the aspects of listening motivation promotion and listening skill development.

In terms of enhancing listening learning motivation, using a mix of open and closed questionnaires to investigate students' attitudes towards YouTube-assisted listening classes, Silviyanti finds that many students believe incorporating YouTube videos into listening classes is more motivating and interesting because students are able to see how the native speaker talk. Moreover, it also points out that YouTube provides less proficient students with adequate audio-visual supports to understand the content better and thus decrease their learning anxiety [21]. In a similar vein, Dirjal et al.'s study explore the potential role of Skype in developing listening motivation and listening skills. The finding reveals offering a real-like communication context: an instant conversation between interlocutors, Skype helps learners overcome language anxiety and thus facilitates listening practice [22].

In terms of developing listening skills, Ayu conducted library research to synthesize theories and research on YouTube videos impacts on listening teaching and concluded several benefits. In particular, in exposing students to authentic materials, students have a chance to analyze and obtain both subject knowledge and linguistic knowledge. For example, assisted by audiovisual aids and video-text, learners can infer the words and speech they heard and, in the meantime, learn the subject contents [23]. What is more, adopting a focus on formal language teaching setting, Mayoral et al. identified YouTube's functions in helping students analyze contraction, speed and tempo of speech [24].

In conclusion, the research aforementioned reveals the positive impacts of social media on language skills development and confirms their efficiency by offering authentic linguistic resources, collaborative platforms and practice opportunities.

\subsection{Social Media as Intercultural Communication Platforms}

\subsubsection{Socio-pragmatic Skills}

To understand language acquisition, Hymes proposes the concept of communicative competence and argues that, in addition to language rules, it is equally essential to comprehend the rules of how to use language in an appropriate way [25]. In other words, language learners need to know "when and how to say what to whom" [26]. To enhance learners' communicative competence, one indispensable path is to develop socio-pragmatic skills and select appropriate linguistic forms according to a given situation. Indeed, according to an ethnographical perspective, each speech community has its own speaking rules that are culturally and historically constructed. To use language appropriately, learners need to be acquainted with the social norms of the target language [27]. Due to its great significance, several studies intended to explore the role of social media in facilitating language learners' socio-pragmatic competence enhancement from various perspectives.

Generally speaking, previous empirical research stresses that social media have been proven to be effective in socio-pragmatic competence enhancement by offering favourable conditions of input and output.

In terms of socio-pragmatic input, many researchers have underscored the difficulty of incorporating sociopragmatic instruction in traditional classrooms where essential input, such as authentic instant feedback from communicators, contextualized scenarios, and reliable linguistic resources, are limited [28, 29]. In contrast, Blattner and Fiori speculated that social media secure an interactive path to the target language community and provide learners with adequate authentic sources that contribute to socio-pragmatic learning by transcending space and time limits. In this regard, the two researchers designed a Facebook project where students are prompted to collect language items and conduct a speech acts analysis of greetings and leave-takings accordingly. By exposing students to more intricate and comprehensive language varieties than traditional classrooms do, Facebook provides students with rich evidence for comprehensible pragmatic analyses. For example, in analysis, students appear to understand formal expressions and informal expressions of speech acts and present a step forward to identify linguistic norms specified in the context of Facebook and come to recognize Facebook communications as a genre [30 31]. In contrast, it may be hard to realize in traditional classrooms.

Another strand highlights social media as stimulations for output, as they afford non-threatening spaces for language learners to experiment and practice what they have learned. According to the pushed output 
hypothesis maintained by Swain, only through production are students able to notice the gap between their production and the target language form and ultimately destabilize the interlanguage representatives [32]. Indeed, Harting's study to explore Facebook as a pragmatic competence development tool for German learners emphasizes the role of Facebook as a production platform that encourages learners to apply their pragmatic knowledge in practice. It reveals that writing and sharing posts with classmates effectively entice learners to notice the nuances between target language expressions and native language correspondences and further encourage learners to investigate the cultural roots [33]. Similarly, the function has also been elucidated in Reinhardt and Ryu's attempt to develop Korean learners' socio-pragmatic awareness by residing on Facebook. To debrief, Facebook provides students with an authentic communication context where they need to produce appropriate Korean honorifics to the corresponding identities of the interlocutors. Centring on learner-generated texts, peers further explored and proofread the productions according to the target expressions for new observations and analysis. This practice has proven effective since students have generally shown an enhanced understanding of contextual constraints on use and socio-pragmatic awareness [34].

\subsubsection{L2 Motivation}

Intercultural contacts provided by social media have been widely acknowledged as a prominent antecedent in enhancing the understanding of socio-cultural affordances of the target language and further evoke positive attitudes to language learning. In other words, they not only promote intercultural competence but also improve language learning motivation. Motivation has been usually understood as "the desire to initiate L2 learning and the effort employed to sustain it" [35]. Due to its great significance in second language development, it has inspired much literature to examine the relationship between social media and language learning motivation and thus generated different conceptualizations.

One trend of language motivation research focuses on the impacts of social media on learners' self-confidence when using the target language. Employing a quantitative method, Lee and Lee investigate if virtual intercultural experiences are correlated with the willingness to communicate. The results suggest virtual intercultural experiences encourage students to communicate by connecting them with diverse target language speakers and increasing understanding of L2 culture. Concerning the research finding, the authors further propose that educators can engage language learners in social media mediated activities to raise their awareness of intercultural experience [36].
Another strand of motivation research concentrates on the potential influences of social media on future selfidentification construction. According to the L2 Motivational Self System, language learning motivation has generally been comprehended as the intended efforts that human beings conduct according to a future selves [37]. The connection between social media and future self-development can be partly attributed to the fact that social media afford language learners low-risk social participations for transnational/cross-cultural identity construction [38]. Focusing on minority students in Hongkong, by developing and examining a structural equation model, Lai's study confirms the paths from social media usage to motivated efforts in Chinese language learning mediated through self-identity evolutions. The study suggests social media as an identity negotiation space where cultural/linguistic minorities can reconstruct a bi-cultural identification that combines both their ethical identity and the mainstream membership. It thus highlights informal social media usage contributes to learners' language learning motivation [39]. Based on the study, Lai and Tai further maintain that social media user needs to be differentiated. With the nuanced perspective, the research initiates another model by dividing social media usage into passive social media activities and active social media activities. The differentiation is supported by data analysis, and the result reinforces that different social media usage leads to different paths to influence language learning motivation [40]. In this regard, for language educators or cultural/linguistic minority people who intend to employ social media as a language learning tool, it is essential to concern not only what to use but also how to use it to facilitate language learning.

In sum, the empirical research reviewed above reveals that social media can effectively promote learners' L2 motivation by enhancing affective emotions and supporting identity (re)constructions.

\subsection{Limitations of Social Media}

Though many benefits of social media usage in the language education context have been explored, they are not free of limitations that require educators and learners' attention. Identifying the potential limitations and problems of social media activities should help educators and learners circumvent the risks in exploiting social media as language learning and teaching tools. Noticed limitations and suggestions are concluded as below.

From the perspective of social media as resourceful input, both learners and educators need to be critical of the linguistic resources received from social media as they may expose learners to culturally inappropriate or linguistically conflicting content. For instance, due to different geographical locations and personal styles, linguistic variants of grammar use and lexical information constitute an amalgam of linguistic 
repertoire. Though some of them can benefit learners as they legitimate and value the use of language variations, others may lead to confusion or even a mistake. In this regard, educators should provide necessary guidance with learners to maximize the pedagogical affordances of authentic online resources. In addition, it should be noted that the cultural contents carried by social media platforms can not fit in every context. That is, one expression that is acceptable in one place might be offensive in another place. As a result, learners need to pay special attention to what they bring to social media and what they obtain from social media [41].

From the perspective of social media as practice places, social media platforms are of various functions ranging from working to entertainment, and students should use the innovative technologies wisely. For example, social media are embedded with interesting content and fascinating functions, which may present as an obstacle for learners to focus on learning. Indeed, in documenting an attempt to incorporating writing activities into online social media platforms, it is reported by Dirjal et al. that sometimes students may forget their online assignments and be distracted by other things on Internet [42]. Moreover, online correction checkers are originally designed to enhance working and interaction efficiency for learners. However, excessively relying on online correction checkers may result in a recess in spelling and grammar [7]. Informed by the potential limitations brought by social media in promoting language learning, learners and educators should be guided through social media platforms features, and frequent teacher-student interactions should be granted to track if students are on the right track. By doing so, the problems mentioned above are hopefully alleviated or removed.

\section{CONCLUSION}

In this review, the study presents an attempt to synthesize potential social media impacts on language learning based on two main perspectives: social media as language skills development platforms and social as intercultural communication platforms. The empirical studies reviewed above suggest social media are effective and efficient in facilitating the language learning process. In the meantime, potential limitations are also concluded, and the study argues that technology is neutral in nature. To maximize the benefits of social media, both educators and learners need to caution the way they perform on social media and how they utilize the technologies.

Informed by the literature mentioned above, several future direction recommendations are made to contribute to the ongoing academic conversations regarding social media research.
First, most of the research concentrates on a few social media platforms, notably Facebook and YouTube. Other media platforms, such as Instagram and local social media platforms, also merit future exploration. Second, underexplored areas such as less popularly taught languages, speaking and listening skills deserve more attention. Moreover, a nuanced perspective is also proposed to explore the specific correlations between social media and language learning. For example, instead of investigating Twitter as a whole, it may be beneficial to look into the impacts of hashtags or the different impacts between active Twitter usage and passive Twitter usage to generate more specific educational implications. Third, social media usage in formal contexts has concluded fruitful results, but studies in informal contexts are relatively limited and appeal for further investigation. Fourth, it has been noticed that the time devoted to examining social media impacts on language learning is often less than one academic semester. In this aspect, a longitudinal approach is within reach to reveal the dynamic changes of language learning over time. For example, in investigating the relationship between social media usage and motivation enhancement, a longitudinal approach is granted, considering motivation and action is not a causal-effect correlation but a bidirectional relationship.

\section{REFERENCES}

[1] Jin, S. (2015). Using Facebook to promote Korean EFL learners' intercultural competence. Language Learning \& Technology, 19(3), 38-51.

[2] Kaplan, A. M., \& Haenlein, M. (2010). Users of the world, unite! the challenges and opportunities of Social Media. Business Horizons, 53(1), 59-68.

[3] Lannin, A. A. (2007). Freewriting for fluency and flow in eighth and ninth grade reading classes. University of Missouri-Columbia.

[4] Stapa, S. \& Majid, A. (2006), The use of first language in limited English proficiency classes: Good, bad or ugly?, e-BANGI, 1(1), 1-12.

[5] Vikneswaran, T., \& Krish, P. (2016). Utilising social networking sites to improve writing: a case study with Chinese students in Malaysia. Technology, Pedagogy and Education, 25(3), 287-300.

[6] Alberth. (2019). Use of Facebook, students' intrinsic motivation to study writing, writing self-efficacy and writing performance. Technology, Pedagogy and Education, 28(1), 21-36.

[7] Shih, R. C. (2011). Can Web 2.0 technology assist college students in learning English writing? Integrating Facebook and peer assessment with blended learning. Australasian Journal of Educational Technology, 27(5), 829-845. 
[8] Wichadee, S. (2013). Peer feedback on Facebook: The use of social networking websites to develop writing ability of undergraduate students. Turkish Online Journal of Distance Education, 14(4), 260270 .

[9] Bandura, A. J. (1997). Self-efficacy: The exercise of control. New York, NY: W. H. Freeman and Company.

[10] Raoofi, S., Tan, B. H., \& Chan, S. H. (2012). Selfefficacy in second/foreign language learning contexts. English Language Teaching, 5(11), 6073.

[11] Prichard, C. (2013). Using social networking sites as a platform for second language instruction. TESOL Journal, 4(4), 752-758.

[12] Vikneswaran, T., \& Krish, P. (2016). Utilising social networking sites to improve writing: a case study with Chinese students in Malaysia. Technology, Pedagogy and Education, 25(3), 287-300.

[13] Nishioka, H. (2020). Learning to write Japanese using a SNS designed to develop writing proficiency: Affordances and constraints. Electronic Journal of Foreign Language Teaching, 17(2), 405-420.

[14] Solmaz, O. (2018). A critical review of research on social networking sites in language teaching and learning. Contemporary Educational Technology, 9(3), 315-330.

[15] Kabilan, M. K., Ahmad, N., \& Abidin, M. J. Z. (2010). Facebook: An online environment for learning of English in institutions of higher education?.The Internet and Higher Education, 13(4), 179-187.

[16] Abdullah, Z. H. A. (2019). The Impacts of Social Media on Kurdish EFL Students' English Language Proficiency. Journal of Tikrit University for Humanities, 27(5), 89-105.

[17] Brown, D. H. (1994). Principles of language learning and teaching. Englewood Cliffs: Prentice Hall Regent.

[18] Namaziandost, E., \& Nasri, M. (2019). The impact of social media on EFL learners' speaking skill: a survey study involving EFL teachers and students. Journal of Applied Linguistics and Language Research, 6(3), 199-215.

[19] Mustafa, E. N. E. (2018). The impact of YouTube, Skype and WhatsApp in improving EFL learners' speaking skill. International Journal of Contemporary Applied Researches, 5(5), 18-31.
[20] Ilyas, M., \& Putri, M. E. (2020). YouTube channel: An alternative social media to enhance EFL students' speaking skill.J-SHMIC: Journal of English for Academic, 7(1), 77-87.

[21] Silviyanti, T. M. (2014). Looking into EFL students' perceptions in listening by using English movie videos on YouTube. Studies in English language and Education, 1(1), 42-58.

[22] Dirjal, A. H., Ghapanchi, Z., \& Ghonsooly, B. (2020). Role of social media application in promoting motivation and listening skill of Iraqi EFL learners: a Skype-Based study. Asian Social Science, 16(8), 20-32.

[23] Ayu, L. P. (2016). YouTube videos in teaching listening: The benefits in experts' views. Research in English and Education Journal, 1(2), 152-160.

[24] Mayoral, P., Tello, A., \& Gonzalez, J. (2010). YouTube Based Learning. Journal of International Federation of Surveyors, 1-12.

[25] Hymes, D. (1972). On communicative competence. In J. B. Pride \& J. Holmes (Eds.), Sociolinguistics: Selected readings (pp. 269-293). Penguin.

[26] Larsen-Freeman, D., \& Anderson, M. (2011). Techniques \& principles in language teaching (3rd ed.). Oxford, UK: Oxford University Press.

[27] Kaplan-Weinger, J., \& Ullman, C. (2014). A framework for doing the ethnography of communication: ethnography of communication reflux. In Kaplan-Weinger, J., \& Ullman, C. (Eds.), Methods for the ethnography of communication: Language in use in schools and communities (pp. 38-59). Routledge.

[28] Kasper, G. (2001). Four perspectives on L2 pragmatic development. Applied Linguistics, 22, 502-530.

[29] Kasper, G., \& Rose, K. R. (2002). Pragmatic development in a second language. Oxford: Blackwell.

[30] Blattner, G., \& Fiori, M. (2011). Virtual social network communities: An investigation of language learners' development of sociopragmatic awareness and multiliteracy skills. CALICO Journal,29(1), 24-43.

[31] Hanna, B. E., \& de Nooy, J. (2003). A funny thing happened on the way to the forum: Electronic discus- sion and foreign language learning. Language Learning \& Technology, 7(1), 71-85.

[32] Swain, M. (1985). Communicative competence: some roles of comprehensible input and comprehensible output in its development. In S.M. 
Gass and C.G. Madden (Eds), Input in second language acquisition (pp. 235-253). Rowley, MA: Newbury House.

[33] Harting, A. (2017). Using Facebook to Improve L2 German Students' Socio-Pragmatic Skills. The EUROCALL Review, 25(1), 26-35.

[34] Reinhardt, J., \& Ryu, J. (2013). Using social network-mediated bridging activities to develop socio-pragmatic awareness in elementary Korean. International Journal of ComputerAssisted Language Learning and Teaching (IJCALLT), 3(3), 18-33.

[35] Ortega, L. (2009). Understanding second language acquisition. London: Hodder.

[36] Lee, J. S., \& Lee, K. (2020). Affective factors, virtual intercultural experiences, and L2 willingness to communicate in in-class, out-of-class, and digital settings. Language Teaching Research, 24(6), 813833.

[37] Dörnyei, Z. (2009). The L2 Motivational Self System. In Motivation, language identity and the L2 self (pp. 9-42). Multilingual Matters.

[38] Greenhow, C., \& Lewin, C. (2016). Social media and education: Reconceptualizing the boundaries of formal and informal learning. Learning, Media and Technology, 41(1), 6-30.

[39] Lai, C. (2019). The influence of extramural access to mainstream culture social media on ethnic minority students' motivation for language learning. British Journal of Educational Technology, 50(4), 1929-1941.

[40] Lai, C., \& Tai, C. P. (2021). Types of social media activities and Hong Kong South and Southeast Asians Youth's Chinese language learning motivation. System, 97, 1-13.

[41] Haryanto, E., Sulistiyo, U., Fransiska, P., \& Yose, I. (2019). English exposure from digital media and its influence on communicative competence: Students' perspectives and experiences. Indonesian Research Journal in Education, 387-406.

[42] Dirjal, A. H., Ghapanchi, Z., \& Ghonsooly, B. (2020). Role of social media application in promoting motivation and listening skill of Iraqi EFL learners: a Skype-Based study. Asian Social Science, 16(8), 20-32. 